\title{
Cooperation and Coordination in
} Socially Monogamous Birds: Moving Away From a Focus on Sexual Conflict

OPEN ACCESS

Edited by:

Elise Huchard,

UMR5554 Institut des Sciences de

l'Evolution de Montpellier

(ISEM), France

Reviewed by:

Per T. Smiseth

University of Edinburgh,

United Kingdom

Lynn Marie Siefferman, Appalachian State University,

United States

*Correspondence:

Simon C. Griffith

simon.griffith@mq.edu.au

Specialty section:

This article was submitted to Behavioral and Evolutionary Ecology,

a section of the journal

Frontiers in Ecology and Evolution

Received: 16 June 2019 Accepted: 13 November 2019 Published: 26 November 2019

Citation:

Griffith SC (2019) Cooperation and Coordination in Socially Monogamous Birds: Moving Away From a Focus on

Sexual Conflict.

Front. Ecol. Evol. 7:455. doi: 10.3389/fevo.2019.00455

\author{
Simon C. Griffith * \\ Department of Biological Sciences, Macquarie University, Sydney, NSW, Australia
}

Socially monogamous birds have provided a major focus of research in the field of sexual selection, providing insight into the evolution of ornaments, sexual dimorphism and sex roles. Following important theoretical work in the 1970's, there has been a continued emphasis on elements of the sexual conflict between socially monogamous partners. The application of molecular tools enabled a significant research investment into the conflict over paternity. The differential allocation hypothesis, has been another well-worked area, focusing attention on the conflict over investment with a current or future partner, and being at the forefront of high-profile work on maternal effects. Whilst the conflict between the sexes has been a fascinating area of evolutionary biology over the past four decades, I will argue that the level of conflict between partners is often overstated, and our understanding of social monogamy is biased by taking the perspective of conflict rather than cooperation. For example, differential allocation in socially monogamous birds can be explained from an entirely cooperative perspective, as can much behavior that is currently associated with sperm competition and the conflict over paternity. With over $80 \%$ of avian species forming socially monogamous bonds that are often life-long and can last for many decades, we need to redress the balance, and focus more attention on the benefits that both males and females gain from establishing, and maintaining socially monogamous partnerships. I highlight behavioral and morphological adaptations that feature strongly in socially monogamous birds, and that are deserving of more attention from the perspective of the high level of inter-individual cooperation and coordination that undoubtedly exists in many species. Whilst the focus of research has begun to shift recently, it will take many years to redress the bias toward sexual conflict that has taken the major share of empirical attention to this point.

Keywords: social monogamy, Aves (birds), divorce, personality \& behavior, coordination, parental care, mate choice

\section{INTRODUCTION}

In some of the earliest work focused on sexual selection in wild animals, Huxley $(1914,1923)$ focused on the elaborate pair displays of two socially monogamous waterbirds. In both the great-crested grebe Podiceps cristatus and the red-throated diver Gavia stellate, Huxley $(1914,1923)$ described the complex multimodal displays incorporating striking ornamental plumage, alongside 
vocal and physical displays that are highly coordinated by the male and female together. Huxley $(1914,1923)$ noted that these displays were more prevalent after, rather than before pair formation and concluded that the primary function of such displays was to strengthen the partnership and improve the fitness of the pair together. In an important paper, reflecting on sexual selection, Huxley (1938) drew an important distinction between traits that evolved primarily to attract mates, and those that may influence the outcome of reproduction by a pair after mate choice has occurred. Huxley (1938) wrote "In most monogamous birds, display begins only after pairing up for the season has occurred," interpreting that the primary function of displays was psycho-physiological, and linked to the synchronization of male and female "rhythms of sexual behavior" and the maturation of oocytes. Huxley's view (1938) of social monogamy was that of a largely cooperative partnership, that complemented and added to Darwin's theory of sexual selection (Darwin 1871), on the basis of his observations of secondary sexual traits that were not easily reconciled by the competition for mates alone. As recently discussed by Symes and Price (2015), Huxley's ideas (from his 1938 paper) were well-cited up to about 1972 when Campbell's book (1972) initiated a focus on mate choice, and elements in that area that developed into what we now understand as of sexual conflict. Symes and Price (2015) wrote "the intensive attention to sexual selection via mate choice has superseded a balanced assessment of the relative importance of sexual selection and sexual stimulation in the evolution of intersexual signaling." In this review, focused on socially monogamous birds, I bring together the work on mate choice, and the recently emerging work on cooperative and social aspects of sexual selection. I will argue that the work on mate choice in socially monogamous birds has tended to take an overly conflict-centric perspective, and this review will hopefully helpfully to redress the balance-putting the social back into our consideration of social monogamy. Behavioral interactions between males and females will include components that vary from those in which the individuals' interests are highly conflicting, along a continuum of variation to those where the interests of the partners are well-aligned and high levels of cooperation are achieved. Behavioral interactions between partners are likely to have evolved under the tension between conflict and cooperation, and appreciating the full range of variation along the continuum between the two will improve our insight into the evolution of behaviors and morphological traits intimately associated with reproduction in socially monogamous organisms.

Sexual selection focuses on the competition between individuals in a population to win mates and produce offspring. Highly polygynous, and sexually dimorphic birds such as the peacock Pavo cristatus, have long been used as the embodiment of sexual selection, and to a large extent research into sexual selection in other species is largely colored by that species. It is intuitive to assume that if we can understand the selective pressure that created the extravagant ornamentation of the peacock, then surely, we can similarly understand the less extravagant secondary sexual ornaments of males in socially monogamous species like the familiar house sparrow Passer domesticus. Indeed, the peacock literature is widely cited in the research literature on sexual selection in socially monogamous species. However, there is a profound difference in the form of sexual selection in the peacock and the sparrow, arising from the prolonged social interaction between males and females in the sparrow, and all other socially monogamous birds. The peahen will gain little from the peacock other than sperm to fertilize her eggs, and the different qualities (carried within that sperm) that the peacock will contribute to his offspring. Mate choice by peahens is therefore relatively unconstrained by other considerations, and as a result there is a significant skew in reproductive success across the male population, with many peahens mating with just a few "best" males (Petrie et al., 1991). By contrast, the female in a socially monogamous species has a more constrained, and complex mate choice decision to make in her choice of partner. First, in a socially monogamous system many males will be paired and thus unavailable as social partners in the short-term. Second, the female is not just optimizing the genetic quality of her offspring, she should also optimize the many other qualities that the male will provide both to her as a social partner (in both the short, and potentially long-term), and to her offspring as their social and genetic father.

The complexity of the mate choice decision in socially monogamous species, within the context of the iteroparous life history of avian species, sets up a range of interesting potential avenues for both sexual conflict and cooperation. I will review the main areas below, starting with those relating to sexual conflict, but will devote more space to the cooperative aspects, given the imbalance in the literature to date (Symes and Price, 2015).

\section{PART I SEXUAL CONFLICT}

Sexual conflict exists because the evolutionary interests of a male and female will not be perfectly aligned over a lifetime in all species which are not obligately genetically monandrous. At a broad level sexual conflict has been well-introduced and reviewed previously (Arnqvist and Rowe, 2005; Wedell et al., 2006; Hosken et al., 2009), and below I will focus on those aspects of sexual conflict that are of particular relevance to social monogamous birds. The drivers of sexual conflict in socially monogamous birds are those aspects of the life-history that cause deviation from genetic monandry, because that will determine the proportion of an individual's reproductive output that will be independent of the current partner. The conflict will affect investment decisions by males and females, as they consider the investment that they will make in future reproductive opportunities with others as part of their individual life-history strategy. The manifestations of sexual conflict in a system will therefore be those behaviors or morphologies that emerge as a result of the selection on individuals to optimize their own fitness in the context of the sexual conflict present. In each section I will introduce the area, before fore-shadowing the reasons why I believe that each phenomenon deserves attention from the alternative perspective-cooperation. 


\begin{tabular}{|c|c|c|c|c|c|}
\hline Species & Reproductive output & Description & $\begin{array}{l}\text { Proportional } \\
\text { output with } \\
\text { partner } 1\end{array}$ & $\begin{array}{l}\text { Sexual } \\
\text { conflict }\end{array}$ & $\begin{array}{l}\text { Partner } \\
\text { cooperation }\end{array}$ \\
\hline Blue tit & 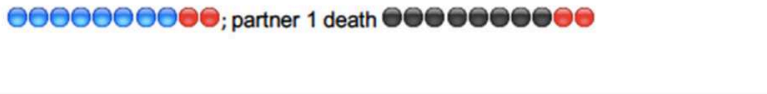 & $\begin{array}{l}\text { Short-lived, mate } \\
\text { replacement after partner } \\
\text { mortality, frequent EPP }\end{array}$ & 0.45 & & \\
\hline $\begin{array}{l}\text { Blue- } \\
\text { footed } \\
\text { booby }\end{array}$ & 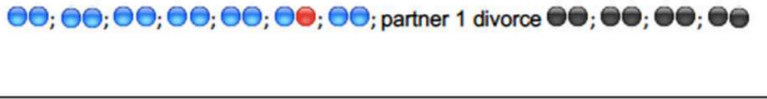 & $\begin{array}{l}\text { Long-lived with } \\
\text { occasional EPP and } \\
\text { divorce }\end{array}$ & 0.59 & & \\
\hline $\begin{array}{l}\text { Zebra } \\
\text { finch }\end{array}$ & 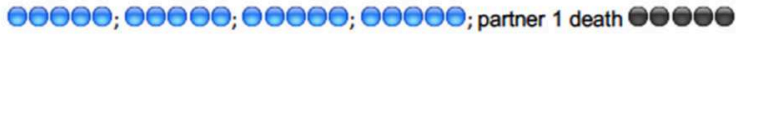 & $\begin{array}{l}\text { Long-lived, no EPP, no } \\
\text { divorce, some mate } \\
\text { replacement after } \\
\text { mortality }\end{array}$ & 0.8 & & \\
\hline$?$ & 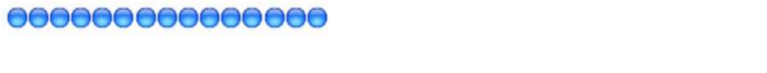 & $\begin{array}{l}\text { Short-lived, highly fecund } \\
\text { with no EPP }\end{array}$ & 1 & & \\
\hline$?$ & 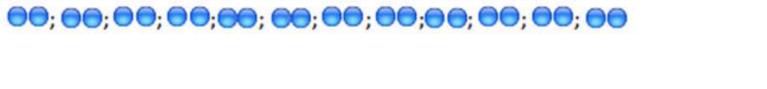 & $\begin{array}{l}\text { Long-lived with no } \\
\text { divorce or mate } \\
\text { replacement }\end{array}$ & 1 & & \\
\hline
\end{tabular}

FIGURE 1 | Illustrating the key drivers of sexual conflict in socially monogamous birds. Reproductive attempts are separated by ";" with eggs produced with a first partner shaded in blue, subsequent partner shaded in black, and extrapair paternity represented with red shading. Sequential monogamy can be driven by the replacement of a mate that dies, or divorce. The three species exemplified are based on approximate levels of EPP, clutch sizes, annual mortality, and divorce. There are no clear avian examples of the two hypothetical situations indicated at the bottom in which there would be lifetime monandry.

\section{Drivers of Sexual Conflict}

\section{Divorce and Sequential Monogamy}

All avian species are iteroparous and although the relatively high investment in parental care will constrain the capacity to rebreed, most individuals have the potential to breed multiple times either within or across years, and reproductive activity extends over a lifetime. Despite some reduced fecundity linked to senescence, long-lived birds remain reproductively active for many decades (Wasser and Sherman, 2010). Exclusive genetic monogamy is unlikely to occur in any avian species because when an individuals partner dies, that individual should take another partner and continue its reproductive life. Furthermore, in many species divorce will be instigated by one, or both partners, usually following sub-optimal reproductive performance by the pair (Culina et al., 2015b). Sexual conflict arises between current partners because the evolutionary trajectories of their individual life-histories are potentially different, and can be individually optimized, with respect to current and future investment (Parker et al., 2002; Arnqvist and Rowe, 2005). For example, one partner may withhold investment in the current brood, toward future investment with another partner. The level of sexual conflict derived through this route is difficult to evaluate across species, but will be driven by the relative rate of mate switching through either divorce or sequential monogamy following partner mortality (Figure 1). The extent of the deviation from complete monogamy-where all pairs breed exclusively together across a whole lifetime-will drive the conflict over the individual investment into reproduction by both the male and female (e.g., Royle et al., 2002). In species that breed over a long period of time, repeat-breeding with the same partner will reduce the level of conflict by increasing the proportion of lifetime reproductive output that is produced with the same partner (see Figure 1). The level of both divorce and annual mortality are very variable in birds (Jeschke and Kokko, 2008) and do not appear to covary strongly (Figure 2). As a result of these two drivers, the level of repeat breeding by individuals, and by pairs together will vary greatly across species and contribute to a likely continuum from high levels of sexual conflict in some species, to high levels of sexual cooperation in other socially monogamous bird species. Whilst there have been many reviews and empirical studies of divorce in birds, there have been fewer studies of the mechanisms and consequences of individuals staying together, even though the data from studies of divorce indicate that this is more common. For example considering the data on 158 species compiled by Jeschke and Kokko (2008) (reported in their supplemental material), there are seven species in which all pairs divorced from one breeding cycle to the next. By contrast all pairs remained together in almost twice as many species (13). Furthermore, the majority of pairs (76\%) remained together for a subsequent breeding attempt across this representative sample of avian species. Surely the mechanisms underlying this social fidelity and the fitness consequences that it drives are worthy of additional attention?

\section{Extra-Pair Paternity}

In the short-term, extra-pair copulations may improve the reproductive success of both males and females, and are known to occur in $76 \%$ of the 255 socially monogamous species surveyed, with extrapair paternity accounting for over half of the offspring in some species (Brouwer and Griffith, 2019). Extrapair paternity provides the opportunity for females to "trade-up," and mate with males of higher quality than their social partner (for good genes benefits for offspring), as well as providing direct benefits such as access to additional resources (through extrapair males) and fertility assurance (Brouwer and 


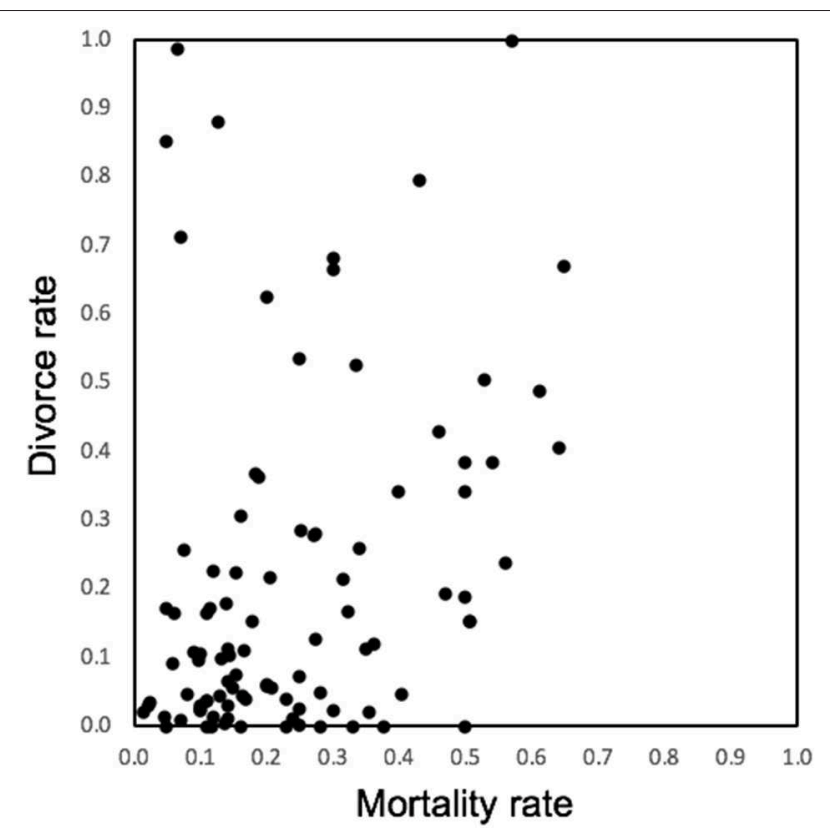

FIGURE 2 | Variation in the rate of mortality and divorce for the 97 species of bird in which both parameters were reported in the supplementary table provided in Jeschke and Kokko (2008). The mortality rate is the proportion of adults that die between 1 year and the next, divorce is the proportion of pairs that are made up of individuals breeding with a new partner when both former partners are still alive (full details and original sources given in Jeschke and Kokko, 2008).

Griffith, 2019). Sexual conflict is inevitable when extrapair paternity exists in a system through a number of routes: any offspring sired by extrapair males will reduce the fitness value of the brood to the pair male; in the absence of reliable cues of kinship, the pair male will invest in offspring that are not his; the care invested by a male in his partner may represent an opportunity cost in terms of missed opportunities to invest in seeking extrapair copulations. In socially monogamous species, sexual conflict will therefore be driven by the incidence and frequency of extrapair paternity. In some species, the level of sexual conflict between partners driven by extrapair paternity will be significant (given the high rates of the latter; Brouwer and Griffith, 2019). However, in many monogamous species, extrapair paternity is low or non-existent, and will not contribute to sexual conflict. There is a clear phylogenetic signal in the level of extrapair paternity across avian species and it is low or completely absent across significant parts of the avian phylogeny (Brouwer and Griffith, 2019). It is arguable that our perspective on extrapair paternity is somewhat biased by the relatively high levels seen in many species of passerine that have been relatively well-sampled (Brouwer and Griffith, 2019), but even here, there are passerines such as the zebra finch in which extrapair paternity is essentially absent (Griffith et al., 2010).

It is noteworthy that the most consistent determinant of the variation of the level of extrapair paternity across species is the annual mortality rate of the species-long-lived species have lower rates of extrapair paternity than short-lived species (Griffith et al., 2002; Botero and Rubenstein, 2012). In those species in which the male and female have the potential to breed with each other over a longer period of time, they tend to remain more genetically faithful to one another. This pattern is consistent with the idea that repeated mating with the same individual will be valuable and shouldn't be compromised by infidelity (see below). Short-lived species, tend to live in highly predictable and seasonally constrained environments (Botero and Rubenstein, 2012), and the current breeding attempt will constitute a higher proportion of an individuals' lifetime reproductive opportunity. As a result, of such limited reproductive opportunities, both males and females should "bethedge" against the poor quality of a partner by engaging in some infidelity. From a female perspective, there is a real risk that if a male partner is functionally infertile (Sheldon, 1994) this can only be detected once a first set of eggs has failed to hatch (after the whole incubation period has elapsed). The opportunity to breed may have passed, not only for that year, but potentially for life.

It is important to recognize that extrapair paternity does not always equate to sexual conflict. There are also social contexts in which even though social males may lose paternity, this does not mean that the evolutionary interests of the male and female are necessarily misaligned. A nice example is the lazuli bunting Passerina amoena, where subordinate males will be permitted to establish territories next to dominant males who will gain extrapair paternity from their low-ranking neighbors (Greene et al., 2000). Even though $49 \%$ of all nests contained extrapair offspring sexual conflict will be reduced in this system because despite the offspring lost to dominant males, subordinate males have higher reproductive success than they would if they didn't nest on those territories (Greene et al., 2000). Furthermore, the reproductive success of the female is improved when paired to subordinate males because she benefits from the territory, and access to the high quality neighboring dominant males (Greene et al., 2000). Therefore, the evolutionary fitness of the male and the female can still be fairly closely aligned in this context, as the extrapair paternity improves the fitness of both members of the pair. Extrapair paternity can certainly contribute to the level of sexual conflict in socially monogamous birds, but the level to which it does so in most species is probably somewhat overstated, with much focus on relatively few species that have high levels (e.g., reed bunting Emberiza schoeniclus, superb fairy wren Malurus cyaneus, tree swallow Tachycineta bicolor) perhaps distorting our perspective (see also Brouwer and Griffith, 2019).

\section{Manifestation of Sexual Conflict Sexual Conflict Over Mate Choice}

In many species physical or acoustic mate guarding is viewed as an adaptive response by males to the threat posed by extrapair males. Mate guarding is often interpreted as direct evidence of sexual conflict (Arnqvist and Kirkpatrick, 2005), and indeed close attention by the pair male will constrain a female's attempt to freely express alternative mate choice. Physical mate guarding is characterized as the close following by a male that intensifies during a female's fertile period. Acoustic mate guarding is characterized as a higher level of male song, and particularly 
duets (in those species in which both male and female sing together), during the peak period of fertility (Rogers et al., 2007). Whilst often interpreted as the manifestation of sexual conflict, it can be difficult to exclude the possibility that close attention of the female by the male partner might be mutually beneficial. For example, zebra finches have been suggested to provide a classic case of successful mate guarding because the pair are always observed together during the fertile period and there is so little extra-pair paternity in the wild (Birkhead et al., 1988, 1990). However more recent data indicates that the pair are almost always together, even when there is no breeding going on in a population (McCowan et al., 2015). Whilst mate guarding undoubtedly occurs in some species (particularly those in which a male has a high risk of losing paternity), and will be a manifestation of sexual conflict, this will not always be the case. As discussed below, behavior formerly considered to be mate guarding, may be cooperative behavior between the pair.

\section{Sexual Ornamentation}

A lot of work has taken the perspective that ornamental traits such as extravagant tails, colors and song, are primarily adverts through which males acquire females (Andersson and Simmons, 2006). As such, investment in the traits by males (usually, but also by females in those species in which they also express such traits), carries a cost to the other sex. The focus on mate choice implies that the ornamented sex will be trading-off investment in parental care with that devoted to continued display. Furthermore, an indirect additional cost, built into the handicap models of sexual ornamentation, is that extravagant ornamental traits will impose direct costs to those expressing them, with respect to increased conspicuousness, aerodynamic performance, or the energetic costs of maintaining, or performing them (song) (Kokko et al., 2002).

In socially monogamous species, whilst ornamental traits will aid females in finding a good quality partner initially, the existence of such traits will impose long-term costs on the investment that they will get from that partner. Particularly in species with long-lived partnerships, there seems to be a logical problem here, perhaps again caused by the conceptual reference to the train of the peacock. In the highly extravagant peacock, the costs of expressing the ornaments are of no consequence to the female beyond mate choice because she will have no social connection to the male after copulation (Petrie et al., 1991). Socially monogamous birds are different because of the association over time between the male and female. A more refined approach should account for the signal and costs that are inherent in the trait of a socially monogamous male both in mate choice itself, but more importantly for the remainder of the lives of the individuals concerned, and from the perspective of a partnership that can run for many decades after mate choice.

\section{Differential Allocation}

The idea of differential allocation, is implicitly a manifestation of sexual conflict over the investment that an individual makes with its current partner vs. a future partner, with Burley (1986) stating: "an individual's own mating attractiveness affects the amount of parental investment it is able to secure from a mate"; and "attractive individuals can restrict their own per-offspring investment and save reproductive effort for future use.” The idea was first proposed after Burley (1986) observed a correlation between the level of ornamentation in male zebra finches and the level of investment by their partners. The idea is intuitively appealing. If a female is currently paired to a male of relatively low quality (due to the constraints of available mates in a socially monogamous system), it may be adaptive to reduce current investment with that partner so that she is more likely to survive and breed again (with residual resources) with a higher quality partner. The hypothesis has been tested in many socially monogamous species and indeed a recent meta-analysis of all the data found some overall support for the idea (albeit with quite small to moderate effect sizes, and only on some aspects of female investment) (Horváthová et al., 2012). The positive relationship between male ornamentation and the investment by a partner is consistent with the logic of the differential allocation (and in each case has been interpreted as a manifestation of sexual conflict). However, an alternative explanation for the same relationship, is that the ornamentation of the male functions as a signal to the female, to help her optimize her investment in line with his current ability (good parent hypothesis; Hoelzer, 1989), something that may be in the pairs interests if they breed together in the future. However, the continued reference to the differential allocation hypothesis over the past three decades, demonstrates the bias toward ideas of sexual conflict over that time. In many socially monogamous species, including the zebra finch, for which the idea was first suggested, pairs form lifelong partnerships that persist until the death of a partner, and so one of the main assumptions underlying the idea of differential allocation is generally not met. Furthermore, in shortlived species, such as the blue tit Cyanistes caeruleus, which has also been well-studied in this context (see references in Horváthová et al., 2012), the annual adult mortality rate is so high that the majority of adults only get one breeding attempt in their lifetime, and therefore future reproductive attempts are stochastically unlikely and should be of lower value irrespective of potential future partner quality than a current attempt. i.e., an individual should not strategically reduce investment in a current reproductive attempt in lieu of a future event that is unlikely to happen.

\section{Patterns of Investment in Parental Care}

Biparental care for developing offspring is the most prevalent system in socially monogamous birds (Cockburn, 2006). When two parents are jointly providing care to their offspring, it is predicted theoretically that both parents are, to an extent investing with a view to their own interests, reducing the overall level of care relative to a uniparental care system (McNamara et al., 2003). Experimental support for this prediction was found in the zebra finch, comparing the quality of offspring reared under either uniparental, or biparental care (Royle et al., 2002). This demonstrates that there is likely to be some degree of sexual conflict in the negotiation over parental care in most socially monogamous birds, given iteroparity and the lack of lifetime genetic monandry. Biparental care is a highly effective strategy in birds, and the most widespread form of parental 
care $(81 \%$ of species; Cockburn, 2006). Whilst there is some level of conflict over investment (e.g., Royle et al., 2002), the provision of biparental care is an inherently cooperative enterprise between a male and female, and we shouldn't place too much emphasis on the conflict, because in many species the lifetime evolutionary interests of the partners have a high degree of overlap. Furthermore, whilst the important study by Royle et al. (2002) is the best attempt to estimate the conflict inherent in the allocation of each partner to biparental care in birds, the study was only able to consider uniparental care by females, not males. A similar, but more comprehensive study of the burying beetle Nicrophorus vespilloides, found evidence of synergistic benefits of biparental care, with offspring faring better when reared by two parents working together, than either the male, or female working alone, when the resources were standardized across treatments (Pilakouta et al., 2018). To date there is no equivalent work in birds demonstrating the possible synergistic benefits of two parents working together.

\section{PART II COOPERATION AND COORDINATION}

Whilst there has certainly been some work following the trail blazed by Huxley and focused on understanding displays within monogamous pairs such as greeting ceremonies, duetting (Odom et al., 2014), allopreening (Kenny et al., 2017), and ritualized copulation (reviewed in Wachtmeister, 2001), the majority of these studies were either conducted before the 1990's, or very recently. The highly relevant book edited by Black (1996) that focused on partnerships in birds, in hindsight now stands more as the marker of the passing of a research area rather than the dawn of a vibrant new field. Over the couple of decades following the publication of that book, the major focus of research effort in socially monogamous birds was focused mostly on the elements of sexual conflict highlighted above. The main questions that remain to be adequately resolved include: What is the value of a good partnership to evolutionary fitness? How is a good partnership made? What are the traits that contribute toward good partnerships? What are the ecological or evolutionary drivers that favor good partnerships?

\section{The Value of a Good Partnership}

To a large extent, it is currently difficult to direct address the value of a good partnership with respect to evolutionary fitness, because it is a question that is about the value of the interaction between two individuals. Huxley $(1914,1923)$ focused on this interaction but perhaps because of his language, this message was lost and confounded by arguments based on group selection (as pointed out by Symes and Price, 2015). As recently clarified (Lyon and Montgomerie, 2012; Roughgarden, 2012), sexual selection is a form of social selection that occurs only in the context of competition for mate choice and fertilizations. Traits that are the focus of sexual selection, are likely to be acted on by a far broader set of selective forces occurring over a range of different social interactions. Thus, as first proposed by West-Eberhard (1983), we should consider trait evolution in the broader context of social selection. The social selection perspective as outlined by Roughgarden (2012), acknowledges that there will be some elements of sexual conflict between individuals, but places greater emphasis on the social negotiation between the partners to ensure the successful production of offspring. Even ornamental traits that have become almost synonymous with the idea of intense inter-individual competition and sexual conflict, can be better viewed from the perspective of a cooperative negotiation between partners that produces the optimal reproductive output of the participants (as outlined below). This framework will require a different way of thinking, and the emphasis needs to be placed on the interaction between a male and a female, rather than simply, for example, a competition amongst the males in a population to be selected to mate, or to fertilize offspring.

The traditional framework of sexual selection in birds (often conceptualized with the example of the peacock) is that males will differ in quality, and that some will have "good genes" be most attractive to females, and fertilize most offspring (i.e., directional selection on sexually selected traits; Andersson and Simmons, 2006). In socially monogamous species, perhaps the differences in quality amongst individuals are of less importance relative to the interaction between the male and the female? In social monogamy when there are so many social aspects to be gained from mate choice, it makes sense for individuals to consider all of the complexities resulting from those. For example, males may provide resources such as nest sites, qualities as a parent, and social and genetic characteristics that may or may not make a compatible partnership.

Three recent studies of zebra finches breeding experimentally in captivity, serve to demonstrate this point. The first study finds that when individual quality is controlled experimentally, pairs that choose each other were $37 \%$ more successful than those that were experimentally forced to breed together (Ihle et al., 2015). A second study, found that whilst there was variance in individual quality of males and females there was no evidence of assortative pairing when individuals were allowed to pair freely (Wang et al., 2017a). The third study found that whilst female fecundity was moderately repeatable over time, the ability of males to correctly identify a female from the top or bottom $10 \%$ (with respect to fecundity), of the population distribution was very modest at best (Wang et al., 2017b). The interpretation of these studies, counter to prevailing views on mate choice in birds, was that individual quality is not a focus of mate choice in the zebra finch, and that behavioral compatibility of the partners was relatively more important (Ihle et al., 2015; Wang et al., 2017a,b). These interpretations are also supported by the evidence discussed below on the characteristics of a good partnership in this and other social monogamous species.

A challenge to examining the fitness effects of good partnerships in birds is that there are often correlations between individual age and quality and partnership duration (Black, 1996). For example, in the mute swan Cygnus olor, there is strong positive assortative mating by age, not just because birds stay together as they get older, but also because they re-pair with birds of a similar age (Auld et al., 2013). 
TABLE 1 | The value of remaining with a partner over multiple reproductive attempts, or the cost of divorcing or losing a partner.

\begin{tabular}{|c|c|c|c|}
\hline Species & Benefit of partner fidelity & Cost of divorce/partner loss & References \\
\hline Blue-footed booby, Sula nebouxii & Breed earlier, higher reproductive success ${ }^{*}$ & & Sanchez-Macouzet et al., 2014 \\
\hline Bearded reedling, Panurus biarmicus & Breed earlier, higher reproductive success ${ }^{* a}$ & & Griggio and Hoi, 2011 \\
\hline Blue tit, Cyanistes caeruleus & & Reduced survival $^{b}$ & Culina et al., 2015a \\
\hline Great tit, Parus major & & Reduced survival $^{\mathrm{b}}$ & Culina et al., 2015a \\
\hline Greylag goose, Anser anser & $\begin{array}{l}\text { Higher testosterone covariation between } \\
\text { partners }\end{array}$ & & Weiß et al., 2010 \\
\hline Oystercatcher, Haematopus ostralegus & Breed earlier; higher reproductive success & & van de Pol et al., 2006 \\
\hline Steller's Jay, Cyanocitta stelleri & Breed earlier, higher reproductive success & & Gabriel and Black, 2012 \\
\hline Zebra finch, Taeniopygia guttata & Faster breeding initiation time ${ }^{*}$ & & $\begin{array}{l}\text { Adkins-Regan and } \\
\text { Tomaszycki, } 2007\end{array}$ \\
\hline Zebra finch, Taeniopygia guttata & $\begin{array}{l}\text { Faster breeding initiation time; increased egg } \\
\text { mass }^{*}\end{array}$ & Increased nestling stress & Crino et al., 2017 \\
\hline $\begin{array}{l}\text { Black brant goose, Branta bernicla } \\
\text { nigricans }\end{array}$ & & Reduced survival $^{\text {b }}$ & Nicolai et al., 2012 \\
\hline
\end{tabular}

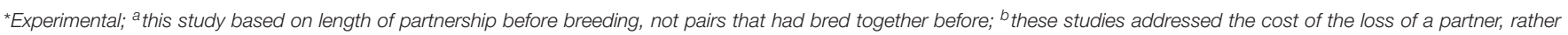
than the cost of the new partner.

In the mute swan, both male and female age contribute independently to the variation in life-history traits like laying date (Auld et al., 2013).

In two long-term studies [blue-footed booby, Sula nebouxii (Sanchez-Macouzet et al., 2014); and the oystercatcher, Haematopus ostralegus (van de Pol et al., 2006)], a sufficient depth of data and mate turn-over through divorce have enabled researchers to statistically partition the effects of the pair-bond, the age, and the quality of the male and female on fitness. In both cases it was found that pairs that were together longer were significantly more successful even after accounting for individual age and breeding experience (van de Pol et al., 2006; SanchezMacouzet et al., 2014). However, in both datasets divorce occurred and was found to be an adaptive decision on the part of at least one of the partners (van de Pol et al., 2006; SanchezMacouzet et al., 2014). There is a reasonably good literature on the costs and benefits of divorce in socially monogamous birds (Choudhary, 1995; Cézilly et al., 2000; Dubois and Cézilly, 2002; Jeschke and Kokko, 2008; Culina et al., 2015b). Divorce appears to be an adaptive strategy in many cases, driven by poor reproductive success with an initial partner (Dubois and Cézilly, 2002; Culina et al., 2015b), and improving the reproductive success of the subsequent reproductive attempt, particularly for females (Culina et al., 2015b). However, it is important to remember that even in the species in which divorce is adaptive in this way (64 species in the Culina et al., 2015b meta-analysis), the majority of pairs remained faithful to one another, and the pairs that divorced, previously had a lower reproductive success than those pairs that remained together (Dubois and Cézilly, 2002; Culina et al., 2015b). Therefore, although some pairs are not very compatible and do not reproduce very well together, in most cases, partner fidelity appears to be valuable. The value of partner fidelity has been identified by a range of recent empirical studies, and generally leads to earlier breeding, and higher reproductive success (studies given in Table 1). Sustained partnerships can also have positive effects on individual survival prospects and effect the physiology of both the adult pair and the offspring (studies in Table 1).

Whilst the positive effects of partnerships are typically investigated over the short-term, a study of long-term partnerships in the oystercatcher, additionally found nice evidence of a decline in reproductive performance in the oldest partnerships which, when experimentally broken, led to the individuals improving when re-paired (van de Pol et al., 2006). The implication here is that even individuals that breed well together and persist over a number of years, might benefit from "refreshing" their social partnership eventually. Whilst divorce is adaptive, and fairly widespread in socially monogamous birds (Choudhary, 1995; Jeschke and Kokko, 2008; Culina et al., 2015b), we should not lose sight of the fact that in most circumstances $(>75 \%)$ pair faithfulness is maintained across years and breeding attempts (see discussion above and the distribution of divorce rates in Figure 2).

The major challenge for researchers in assessing the evolutionary significance of a partnership is the necessity to focus on the interaction between two individuals, rather than just the phenotypes of the two individuals. The expectation is that selection will act on an emergent property of the pair together, such as a measure of behavioral (e.g., Spoon et al., 2006; Mariette and Griffith, 2015) or physiological coordination (e.g., Weiß et al., 2010). An alternative, but challenging way to address the social selection at the heart of social monogamy is to investigate the performance of individuals breeding with multiple different partners to partition individual variation in quality, and that attributable to the interaction between males and females. Although this approach can be taken with very long-term datasets from the wild (e.g., van de Pol et al., 2006; Sanchez-Macouzet et al., 2014), such observational studies are subject to biases (such as the confound of site fidelity, e.g., Cézilly et al., 2000) and are logistically challenging. To date, whilst the studies in Table 1 have demonstrated the value of continued rather than new partnerships, they have not examined the extent 
to which reproductive fitness is driven by social rather than individual selection. An exciting challenge remains the extent of variation in reproductive fitness that comes from individual variance in both male and female quality, and the variance that comes from the interaction between combinations of males and females. It may be possible to address this question with a captive species, such as the zebra finch, in which individuals could be systematically force-paired multiple times experimentally, to determine both individual, and pair interactive, determinants of success. However, it will remain a real challenge to address the question in an ecologically relevant setting in which all of the normal drivers of selection on the partnership are in operation.

Relatively little work to date has characterized the nature and value of partnerships outside of the context of breeding, even though in many socially monogamous species the male and female are intimately associated through non-breeding periods of the year (e.g., Tobias et al., 2011; McCowan et al., 2015). In their study of several species of Neotropical antbird, Tobias et al. (2011) demonstrated that pairs foraged and sang duets together throughout the year (including non-breeding periods), largely to defend their territory -a cooperative enterprise. There is a lot of scope for future studies to consider the ecology of pair-bonds in socially monogamous birds outside the breeding context and the value of non-breeding associations to fitness.

\section{Making a Good Partnership}

The recent studies discussed above (Ihle et al., 2015; Wang et al., $2017 \mathrm{a}, \mathrm{b})$ suggest that we may be over-emphasizing the role of mate choice for ornamental traits in many socially monogamous species. For many species, mate choice may occur once early in life and then, in species with high rates of high fidelity may not occur again for many decades and across multiple breeding attempts, because individuals will remain with the same partner. This is well-established in many long-lived birds such as the mute swan or guillemot Uria aalge, where partners have been recorded making repeated breeding attempts over many successive years (Jeschke et al., 2007; Auld et al., 2013). Even in short-lived passerines such as the zebra finch, pairs will often breed together for life, and given the multiple breeding attempts possible in a year that might represent over a dozen breeding attempts in a typical lifespan (Zann, 1996).

In species in which individuals form long-lasting bonds and breed together over multiple attempts, and years, it could be argued that choosing a mate is particularly important, given the long-term nature of that partnership. However, an alternative perspective, is that the success of an individual over such a longterm is unlikely to be easily predicted by phenotypic variation at the point in time when mate choice is made, often many years earlier. In many species, the value of sticking with a partner selected at an earlier point in time, appears to outweigh the alternative strategy of switching to a different individual. This is despite the statistical likelihood over time that the relative intrinsic quality of potential alternative partners encountered must increase with encounter rate, given a normal distribution of intrinsic quality. Whilst as we have seen some individuals do trade-up in this way (Jeschke and Kokko, 2008; Culina et al., 2015b), most pairs do sustain social pair bonds across multiple reproductive attempts. The interpretation of this is surely that whilst the intrinsic quality of a partner is likely to be important, it is trumped by the value of breeding again with a known individual. A second conclusion is that in many species, at the beginning of a breeding season, the majority of individuals will not be choosing partners, they will be staying with the partner they already have.

The consequence of this, is that in many species, the songs or ornaments that researchers have invested so much effort studying in the context of mate choice (and more broadly in sexual selection) will not be used by many individuals in a population in active mate choice, in a given year. This makes sense when we also consider that some traits, such as the song of the zebra finch, is expressed continuously throughout many subsequent years long after an individual has been chosen as a partner. This suggests that the primary function of such traits in socially monogamous species is in the maintenance of a good partnership, rather than the creation of one in the first place (reviewed in Wachtmeister, 2001). A caveat is that in some species, even though social mate choice might not occur each season, as partners stay together, sexual ornaments may also play a role in the pursuit of extrapair paternity by males. Here again though, the rate of extrapair paternity is likely to be too low in many socially monogamous species (it occurs in about $70 \%$ of species, and accounts for about $19 \%$ of offspring in these species; Brouwer and Griffith, 2019), to make the pursuit of extrapair pair paternity the primary function of sexual ornaments in a general sense.

Even in species in which partnerships are typically shorter in duration, such as the seasonally migratory pied flycatcher Ficedula hypoleuca, females appear to choose territories and nest sites rather than males themselves (Alatalo et al., 1986), and on arrival at the breeding grounds visit relatively few males and make a decision within a couple of days (Dale et al., 1992). Zebra finches also form partnerships very quickly in experimental contexts, even when faced with a limited choice of males, with almost $70 \%$ of single individuals forming a partnership within $24 \mathrm{~h}$ when given the opportunity (Rutstein et al., 2007). Whilst the ability to choose a partner is important (Ihle et al., 2015), females are choosing relatively quickly and from a limited pool of males available. This is not surprising, given the constraint of mate choice in a socially monogamous system, in which most males are not available, most of the time.

Possibly because it is relatively accessible part of life-history to assay experimentally, there has been an over-emphasis on mate choice in socially monogamous birds that often does not reflect the ecological or evolutionary significance of mate choice. Studies of the zebra finch again highlight this disconnect. This is one of most widely studied socially monogamous species with respect to mate choice (e.g., Forstmeier and Birkhead, 2004; Rutstein et al., 2007), with experimental trials typically focused on individuals that have been kept in single sex groups for long periods before being given the opportunity to choose a mate and perhaps breed, before being split up and single sexed housed again before the next set of trials (reviewed in Griffith et al., 2017). This creates an illusion that zebra finches have periods during which they are not paired. However, in the wild, they pair for life, and remain closely associated with their partner, roosting and moving around 
together, even when ecological conditions are not suitable for breeding (Zann, 1996; McCowan et al., 2015). In the wild, for most of the time, there will be few individuals seeking a mate, and few individuals of the opposite sex for them to choose from.

The process of mate choice in socially monogamous species is deserving of more attention, because it will help to identify the broader range of benefits that partners can bring over an appropriate timeframe, as well as helping to resolve the point at which pair bonds are actually established, and on what basis. In migratory species that arrive at the breeding grounds shortly before the resumption of reproductive activity, after migratory journeys that differ phenologically for males and females, it is possible to ascertain when mates are chosen, and the mechanisms through which it occurs (e.g., Dale et al., 1992). For other avian species it is less obvious when mate choice is occurring. For sedentary species, males and females interact throughout the year and possibly choose partners on the basis of these long-term interactions. A good example of such long-term mate preference is provided by the superb fairy wren Malurus cyaneus, in which females select males as both social and extrapair partners on the basis of the timing of the molt into the nuptial plumage between 1 and 5 months prior to the start of the breeding season (Dunn and Cockburn, 1999).

New tracking techniques such as PIT tags that can accurately monitor individuals spatially and temporally, within their complex social networks (e.g., Psorakis et al., 2015; Brandl et al., 2019), will provide insight into the timing of mate choice, and the mechanisms through which both males and females establish new partnerships, and dissolve existing ones. Such studies will also help to elucidate the broader range of ecological contexts in which partners operate, and particularly those outside the period of reproductive activity that have been largely neglected to date. For example, a couple of recent studies have identified the benefits of partnerships on overwinter survival (e.g., Nicolai et al., 2012; Culina et al., 2015a), which could be driven by the social benefits of working as a close partnership in a non-reproductive capacity. For example, roosting together could provide significant energetic benefits, and pairs can also act as sentinels for each other-mutual defense (e.g., Fedy and Martin, 2009; Mainwaring and Griffith, 2013). In cooperatively breeding birds, studies recognize these and other social benefits of group living, but these have rarely been considered in socially monogamous pair-living species, and are worthy of further attention.

Given the amount of time that partners spend together on a daily basis, and the long duration of the pair-bond in many socially monogamous birds, it seems likely to be important that partners are behaviorally compatible with one another. Over the past decade, an increasing number of studies have identified assortative mating on the basis of personality variation in a variety of species (summarized in Table 2). It makes sense to pair with a partner that is behaviorally compatible (e.g., Schuett et al., 2011b), and for this to lead to greater reproductive success (e.g. Schuett et al., 2011a). For example, if partners move around together it will be better if they are well-matched in terms of exploratory behavior. By contrast, with respect to personality traits like boldness, or dominance it may be better for partners to mate counter-assortatively, so that the partnership has a mixed combination of such traits, as two bold, or dominant individuals in a single partnership might not work effectively, or clash. The compatibility of a potential partner with respect to inherent behavioral variation should certainly play a role in mate choice. In addition, as discussed below, compatibility on the same, or similar traits is something that can develop over time in a long-term partnership. For example, there are a few studies (in Table 2), that have considered the hormonal compatibility of pairs (e.g., Weiß et al., 2010; Ouyang et al., 2014), but in all such studies, these measures were taken after the formation of the pair, and hence may not represent the formation of partners that are intrinsically similar with respect to hormone levels, but rather, have become coordinated over time.

\section{Developing and Sustaining a Good Partnership}

As suggested above, regardless of the phenotypes on which a male and female initially choose one another in pair formation, probably the most important thing is forging a good partnership and potentially sustaining it over the long-term. The zebra finch is a useful example here. Whilst pairs do better reproductively when they are allowed to choose one another (e.g., Ihle et al., 2015), when individuals are force-paired experimentally, or find a partner from a very limited choice of individuals they will usually remain faithful to that partner long into the future irrespective of later opportunities to divorce and re-pair. The reason for this is likely to be that individuals invest some time initially forging a bond that becomes more valuable over time. The partnership grows, and behavioral, and physiological coordination emerges over time. Many of the studies listed in Table 2, have studied behavioral or physiological synchrony or coordination in already established pairs, and are thus likely focused on this emergent property of the pair, rather than the correlation between the inherent differences between the individuals. The extent to which this is the case is interesting, but there is no current data available to address this question. Longitudinal work addressing the inherent characteristics of individuals before the partnership is formed, and then through the development of the pairbond and over time would be very insightful.

The establishment of a new partnership, or the sustenance of an existing one, are likely to be the primary function of the displays and ritualized performance that drew the attention of Huxley (1914, 1923). The iconic dance of the great-crested grebe, or the well-known bill fencing displays of long-lived seabirds when they re-unite at their breeding sites can be often expressed regularly for a period of weeks before copulations, egg-laying and incubation begin. As Huxley (1938) suggested, it seems very likely that such displays are an important component of developing an effective partnership, and certainly they are expressed long after mate choice has occurred. Developing the behavioral and physiological readiness and coordination of the male and female so that they are tune with one another temporally, is likely to be an important determinant of fitness, and probably requires a degree of 
TABLE 2 | Studies supporting behavioral or physiological compatibility of partnerships in socially monogamous species.

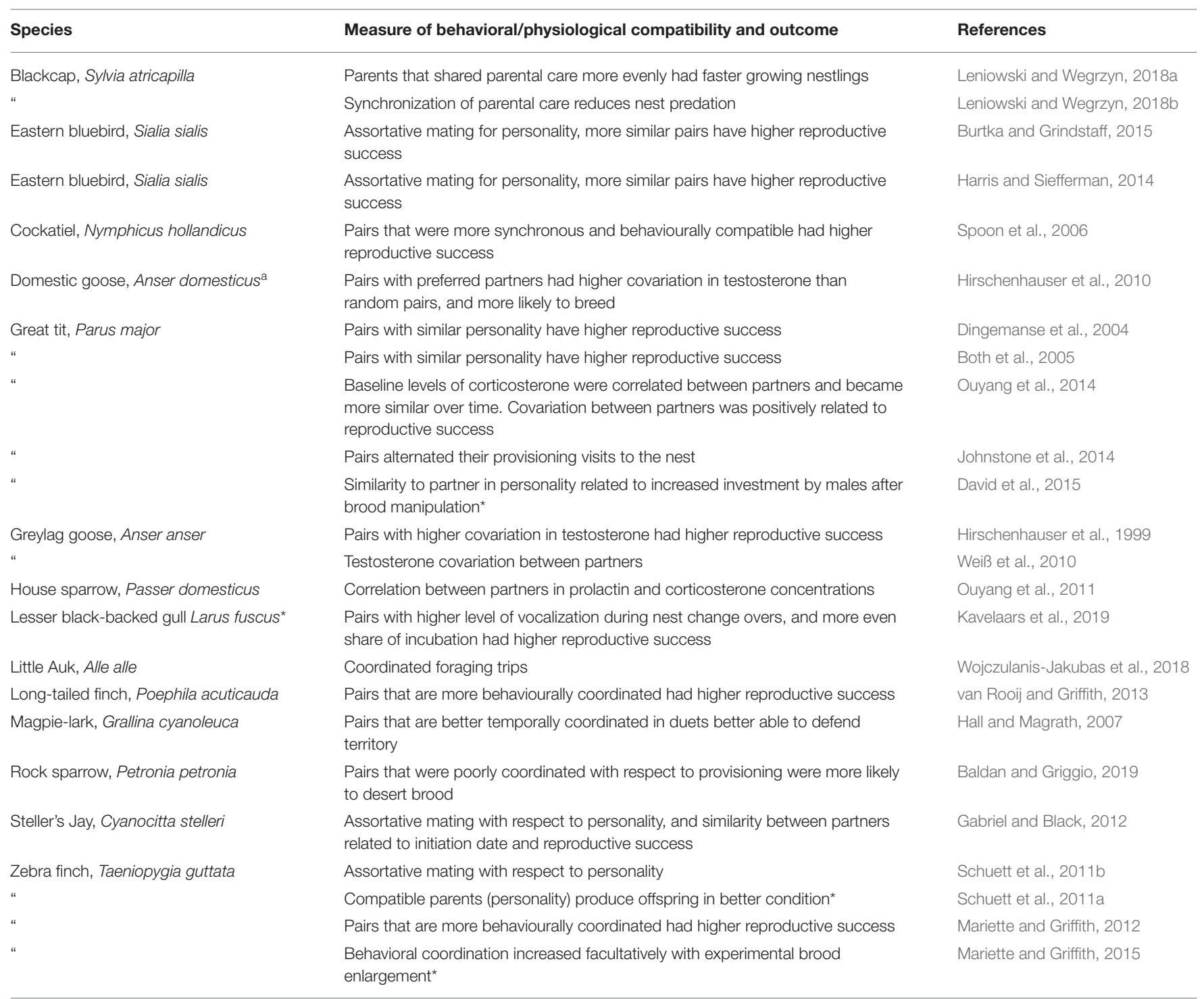

${ }^{*}$ Experimental work. ${ }^{a}$ These were monogamous pairs but the species is typically socially polygynous.

synchrony. Most species of bird significantly reduce the mass of their reproductive tissue and gonads during extended periods of non-breeding (Hahn et al., 2009). Although typically, the recrudescence of gonads may be initiated by photostimulation, particularly in high latitude seasonal breeders, a certain amount of fine tuning and additional stimulation may still be required (Hahn et al., 2009). The development of the male and female gonads, and reproductive tissue, has a different timeframe and pattern of investment in the two sexes and ultimately has to be ready to function effectively at the same time-the relatively short fertile period of the female. In their recent paper, focused on the pine siskin Spinus pinus, Watts et al. (2016) demonstrated the importance of the presence of a partner, and the degree of pair affiliation, for the development of ovaries, the brood patch, and the expression of luteinizing hormone. The stimulatory effect of a partner on the endocrine system and reproductive readiness may operate through a whole range of modalities and whilst there is evidence for acoustic stimulation (e.g., Bentley et al., 2000), at seems likely that a wide range of rituals, and signals are likely to play a role in this physiological synchrony.

In his review, Wachtmeister (2001), identified a range of behaviors that occur regularly in socially monogamous birds after mate choice has taken place, including nest relief, greeting and triumph ceremonies; duetting; allopreening; ritualized copulation and extended periods of courtship. Wachtmeister (2001), does discuss the potential function of these displays in the context of reproductive synchrony and pairbond strengthening. However, both in the abstract and discussion Wachtmeister (2001) places more emphasis on the idea that they may have evolved as a mechanism through which the partners may exploit each other (i.e., an overtly evolutionary conflict argument). This 
perspective is interesting, and remains largely untested, but Wachtmeister's (2001) ideas about sexual conflict as a route to the evolution of these displays provides another example of the propensity for researchers to have looked for sexual conflict even where cooperation seems more intuitively likely.

Recent work has begun to focus in more detail on some of these inter-partner displays and behaviors. In their excellent paper, Odom et al. (2014) identify the prevalence of female song in the majority of passerine families throughout the world, and suggest that these are likely to have been the focus of social selection, rather than sexual selection (which is the main perspective through which song evolution has been studied to date). In their inter-specific examination of allopreening, Kenny et al. (2017), nicely show that allopreening is associated with long-term partner fidelity across seasons, with an analysis of evolutionary transitions indicating that it has evolved (numerous times) in taxa in which there is a high level of parental cooperation or long-term mate retention.

In addition to driving the physiological and behavioral coordination required for a successful reproductive attempt, it seems likely that these displays between partners (after mate choice) may also act as an important source of information, or negotiation between a pair. Reproduction is the most important and often costly thing that an individual will do in its lifetime, and there are a range of difficult decisions to be made. For example, when to breed? Where to breed? Where to put the nest? How much to invest in each episode of reproduction? How long to wait before breeding again?

There is certainly selection on the individuals to optimize these life-history parameters for themselves. In socially monogamous species, and particularly those with long-term bonds and lots of opportunities for multiple breeding attempts over time, there is additionally a significant amount of social selection for optimal decision-making that accounts for the interactive fitness of both partners (Roughgarden, 2012). To achieve optimal reproductive success over the lifetime of the partnerships we would expect significant levels of honest information transfer and negotiation between the partners. The female is ultimately responsible for determining the timing of breeding and the level of investment in a particular reproductive attempt i.e., when the eggs are laid, and how many are laid. It has long been acknowledged that such important life-history decisions are optimized with respect to individual quality (i.e., Pettifor et al., 1988). However, given the importance of male contributions to parental care in socially monogamous systems, it should pay for a female to consider the quality of her partner and his capacity to provide care when making her investment decisions. Furthermore, providing honest information on quality, or offspring rearing capacity should be selected in males, because any dishonesty in information transfer might lead to a sub-optimal investment, with short-term and long-term consequences given the costs of parental care on offspring survival and quality and that of the parents, but also on the males themselves (Bleu et al., 2016). We should thus consider a socially monogamous pair as a team, working together to produce as many offspring as they can over a long-term collaboration (Roughgarden, 2012), and negotiation and information sharing

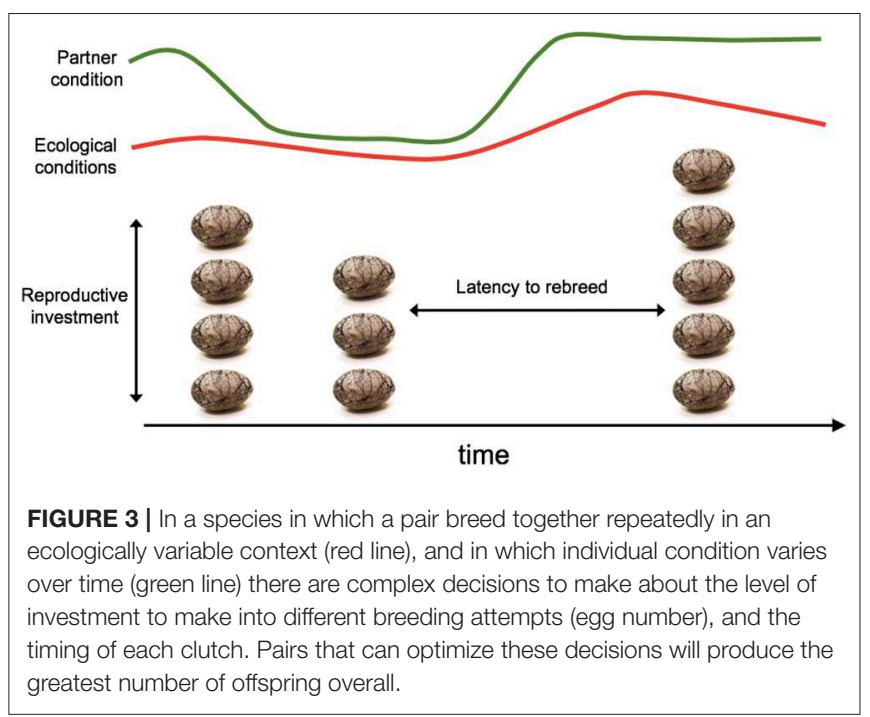

should be at the center of that. Figure 3 illustrates a relatively simple situation for a pair that remain together across a period of time in which ecological conditions suitable for reproduction varies, and so does partner condition. The parameters that a pair should be able to optimize for their long-term fitness include the timing of breeding events both in the context of ecological conditions, individual condition and also with respect to the own breeding events (i.e., latency to re-breed). Reproductive investment can also be varied across multiple events, with a pairs' fitness optimized when clutch sizes are well-matched with extrinsic and intrinsic conditions. These decisions will presumably be easier and/or better when the pair are more coordinated and can communicate and negotiate more effectively with each other.

The expectation from the social perspective of social monogamy (Roughgarden, 2012), is that a variety of phenotypes will have evolved to facilitate good information exchange between the males and females, and contribute to joint decisionmaking over investment. A nice example of such collaborative behavior has been described in the blue-footed booby, as a pair decide on the positioning of a nest over an extended period before a decision on nest site location is reached (Stamps et al., 2002). The pair collaborate by inspecting multiple different potential sites as using "nest-pointing" signals to express individual preference, and exploring additional options if agreement can't at first be reached over a preferred site (Stamps et al., 2002). Similarly, acoustic interactions by a pair, such as duets, can easily be seen as part of a negotiation between partners (Hall and Magrath, 2007; Boucaud et al., 2017; Kavelaars et al., 2019). However, we can also view a much broader range of signals through a similar prism, including many that to date have been regarded as primarily signals involved in mate choice, and under the cloud of sexual conflict (Andersson and Simmons, 2006). Sexual ornaments such as song, and coloration are widely found to be condition-dependent (Kokko et al., 2002), and related to reproductive success and allocation decisions by females, through the perspective of differential allocation, and implicit 
sexual conflict (Horváthová et al., 2012). Even the good parent hypothesis (Hoelzer, 1989), primarily sees such ornamental traits as instruments of mate choice.

The social selection perspective (Roughgarden, 2012), views such signals primarily as part of a communication between team members, to enable effective investment decisions, and this seems far more likely in socially monogamous birds. The interesting thing is that decades of empirical findings in sexual selection aren't wrong, they just need to be re-interpreted. Indeed, to a large extent, signals of quality or condition in males and females are still likely to be used in mate choice decisions, and therefore will be related to attractiveness. Importantly, however, in the longer-term the continued expression of such traits should not be viewed as part of some alternative strategy that undermines the partnership and represents sexual conflict, but that strengthens the partnership and improves its collective fitness. In socially monogamous birds, the ornamental phenotypes of a male should be viewed as an honest signal, primarily to his partner, of his quality and condition. This helps the female to strategically adjust her reproductive investment in line with his ornamentation. If he is in good condition, she will invest more than if he is currently in poor condition (see also Figure 3). That will give qualitatively the same pattern of investment with respect to ornaments as predicted by the differential allocation hypothesis, but it makes more sense in the context of a socially monogamous partnership where cooperation should take precedent over conflict. The honesty of the signal by the displaying sex (usually males), is maintained by the overlapping interests of the partners in both the short- and long-term. In the short-term, the more information parents have about each other's condition, the better the quality of care will be as conflict over investment is resolved (Johnstone and Hinde, 2006). Furthermore, the cost of a male producing an unreliable signal will be sup-optimal investment by his partner, which will reduce his fitness, and compromise his relationship with his partner. The latter will be particularly costly in the many species in which there are clear benefits of repeat breeding (e.g., see Table 1). So, to be clear, if a male signals that he is currently in lower than average condition, it makes sense for his partner to reduce investment in the current reproductive attempt. The offspring in a brood of reduced size will fare better given his reduced ability to feed them. Furthermore, he will not be overstretched through his investment in the current reproductive effort and that will positively affect his ability to survive and invest more in future reproductive attempts. That will be of great benefit to his partner when the value of reproducing with a known partner exceeds any benefits of taking a new partner.

The extent to which such collaborative signals evolve will likely depend on the extent to which the evolutionary interests of the male and female overlap (i.e., the extent of lifelong monogamy). In their recent model, Servedio et al. (2013) modeled the evolution of mutual signals in socially monogamous species and took the perspective that many such traits may have evolved to "manipulate" the other partner into greater parental care. It is possible that there is a continuum between manipulation and collaboration, operating across different socially monogamous species, which is worthy of further theoretical investigation.
In a collaborative partnership we should expect good communication between partners and patterns of investment that optimize the fitness of the pair over the long-term. Nesting displays, courtship feeding, courtship rituals, sexual ornaments (e.g., color, song), allopreening, duetting, coordinated care, mutual defense, should all be viewed as playing an important part of partnership building and maintenance, that have evolved in part through the process of social selection (Lyon and Montgomerie, 2012; Roughgarden, 2012). We should expect that partners that can communicate and negotiate more effectively will have higher fitness (e.g., Kavelaars et al., 2019).

\section{The Ecology and Evolution of Strong Partnerships in Socially Monogamous Birds}

The extent of cooperation or conflict between socially monogamous partners should depend on the extent of repeated interactions between them, and also the complexity of the reproductive decisions that need to be made. We would expect long-lived species, with low divorce rates to have more cooperative partnerships than shorter-lived species, or those with higher divorce rates, because of the likelihood of repeated interactions over time. As illustrated in Figure 1, the key driver is the number of repeated reproductive opportunities that a pair will have as a proportion of their lifetime output. Cooperation will be favored between partners when there is a higher degree of overlap between the lifetime output of an individual and that of their partner. Comparative work on a variety of traits fits this expectation, with longevity negatively related to the level of genetic infidelity (Griffith et al., 2002), and divorce (Botero and Rubenstein, 2012). Pairs that breed together repeatedly are more likely to engage in allopreening, and this is also correlated with the level of parental cooperation over care (Kenny et al., 2017). Ecologically, reproductive decisions should be more complicated toward the tropics rather than at high latitudes, because breeding seasons are typically longer, and timed with respect to climate and ecological conditions (Englert Duursma et al., 2017, 2018). As such, individuals (and pairs), have more complicated decisions about when to breed, how many times to breed during an extended breeding season and how to spread investment across multiple attempts rather than just one annual attempt. Slater and Mann (2004) suggested that the prevalence of female song in the tropics is likely due to the importance of better integration and the difficulty of timing breeding. This idea has yet to be tested, but divorce and infidelity are related to the predictability of the climate (Botero and Rubenstein, 2012), and true cooperative breeding is related to environmental uncertainty in the same way (Jetz and Rubenstein, 2011).

With respect to longevity, Wasser and Sherman (2010) found that longer-lived birds breed more socially, with the latter combining both colonial and cooperatively breeding species. These studies suggest that perhaps the level of cooperation in a socially monogamous partnership, is likely to be driven by broadly similar determinants as cooperation between adults in cooperatively breeding birds, or those seen between conspecifics 
in avian species that breed at high density. Given the prevalence of social monogamy and biparental care across the avian group (Cockburn, 2006), and the heterogeneity that is likely to exist in the duration and strength of the partnership across these species, this could be a very fruitful ground for studies in the evolution of sociality. Hopefully, in the future, studies of cooperation in socially monogamous birds will start to outnumber those looking for conflict, to redress the balance from the past few decades. An exciting challenge to future work addressing the nature and extent of cooperative partnerships in birds arises from the often

\section{REFERENCES}

Adkins-Regan, E., and Tomaszycki, M. L. (2007). Monogamy on the fast track. Biol. Lett. 3, 617-619. doi: 10.1098/rsbl.2007.0388

Alatalo, R. V., Lundberg, A., and Glynn, C. (1986). Female pied flycatchers choose territory quality and not male characteristics. Nature 323, 152-153. doi: $10.1038 / 323152 \mathrm{a} 0$

Andersson, M., and Simmons, L. W. (2006). Sexual selection and mate choice. Trends Ecol. Evol. 21, 296-302. doi: 10.1016/j.tree.2006.03.015

Arnqvist, G., and Kirkpatrick, M. (2005). The evolution of infidelity in socially monogamous passerines: the strength of direct and indirect selection on extrapair copulation behavior in females. Am. Nat. 165, S26-S37. doi: $10.1086 / 429350$

Arnqvist, G., and Rowe, L. (2005). Sexual Conflict. Princeton, NJ: Princeton University Press.

Auld, J. R., Perrins, C. M., and Charmantier, A. (2013). Who wears the pants in a mute swan pair? Deciphering the effects of male and female age and identity on breeding success. J. Anim. Ecol. 82, 826-835. doi: 10.1111/1365-2656.12043

Baldan, D., and Griggio, M. (2019). Pair coordination is related to later brood desertion in a provisioning songbird. Anim. Behav. 156, 147-152. doi: 10.1016/j.anbehav.2019.08.002

Bentley, G. E., Wingfield, J. C., Morton, M. L., and Ball, G. F. (2000). Stimulatory effects on the reproductive axis in female songbirds by conspecific and heterospecific male song. Horm. Behav. 37, 179-189. doi: 10.1006/hbeh.2000.1573

Birkhead, T. R., Burke, T., Zann, R., Hunter, F. M., and Krupa, A. P. (1990). Extra-pair paternity and intraspecific brood parasitism in wild zebra finches Taeniopygia guttata, revealed by DNA fingerprinting. Behav. Ecol. Sociobiol. 27, 315-324. doi: 10.1007/BF00164002

Birkhead, T. R., Clarkson, K., and Zann, R. (1988). Extra-pair courtship, copulation and mate guarding in wild zebra finches taeniopygia guttata. Anim. Behav. 36, 1853-1855. doi: 10.1016/S0003-3472(88)80133-7

Black, J. M. (1996). Partnerships in Birds - The Study of Monogamy. Oxford: Oxford University Press.

Bleu, J., Gamelon, M., and Sæther, B.-E. (2016). Reproductive costs in terrestrial male vertebrates: insights from bird studies. Proc. R. Soc. B Biol. Sci. 283:20152600. doi: $10.1098 / \mathrm{rspb} .2015 .2600$

Botero, C. A., and Rubenstein, D. R. (2012). Fluctuating environments, sexual selection and the evolution of flexible mate choice in birds. PLOS ONE 7:e32311. doi: 10.1371/journal.pone.0032311

Both, C., Dingemanse, N. J., Drent, P. J., and Tinbergen, J. M. (2005). Pairs of extreme avian personalities have highest reproductive success. J. Anim. Ecol. 74, 667-674. doi: 10.1111/j.1365-2656.2005.00962.x

Boucaud, I. C. A., Perez, E. C., Ramos, L. S., Griffith, S. C., and Vignal, C. (2017). Acoustic communication in zebra finches signals when mates will take turns with parental duties. Behav. Ecol. 28, 645-656. doi: 10.1093/beheco/arw189

Brandl, H. B., Farine, D. R., Funghi, C., Schuett, W., and Griffith, S. C. (2019). Early-life social environment predicts social network position in wild zebra finches. Proc. R. Soc. B Biol. Sci. 286:20182579. doi: 10.1098/rspb.2018.2579

Brouwer, L., and Griffith, S. C. (2019). Extrapair paternity in birds. Mol. Ecol. 28, 4864-4882. doi: 10.1111/mec.15259

Burley, N. T. (1986). Sexual selection for aesthetic traits in species with biparental care. Am. Nat. 127, 415-445. doi: 10.1086/284493 very tight and relatively long duration of pair bonds. Longer pair bonds, and higher levels of cooperation, will make it more difficult to disentangle the effect of individual phenotype on fitness and those aspects that are an emergent property of the partnership itself.

\section{AUTHOR CONTRIBUTIONS}

The author confirms being the sole contributor of this work and has approved it for publication.
Burtka, J. L., and Grindstaff, J. L. (2015). Similar nest defence strategies within pairs increase reproductive success in the eastern bluebird, Sialia sialis. Anim. Behav. 100, 174-182. doi: 10.1016/j.anbehav.2014.12.004

Campbell, B. G. (1972). Sexual Selection and the Descent of Man 1871-1971. Chicago, IL: Aldine Pub. Co.

Cézilly, F., Dubois, F., and Pagel, M. (2000). Is mate fidelity related to site fidelity? A comparative analysis in Ciconiiforms. Anim. Behav. 59, 1143-1152. doi: 10.1006/anbe.2000.1422

Choudhary, S. (1995). Divorce in birds: a review of the hypotheses. Anim. Behav. 50, 413-429. doi: 10.1006/anbe.1995.0256

Cockburn, A. (2006). Prevalence of different modes of parental care in birds. Proc. R. Soc. B 273, 1375-1383. doi: 10.1098/rspb.2005.3458

Crino, O. L., Buchanan, K. L., Fanson, B. G., Hurley, L. L., Smiley, K. O., and Griffith, S. C. (2017). Divorce in the socially monogamous zebra finch: hormonal mechanisms and reproductive consequences. Horm. Behav. 87, 155-163. doi: 10.1016/j.yhbeh.2016.11.004

Culina, A., Lachish, S., and Sheldon, B. C. (2015a). Evidence of a link between survival and pair fidelity across multiple tit populations. J. Avian Biol. 46, 507-515. doi: 10.1111/jav.00661

Culina, A., Radersma, R., and Sheldon, B. C. (2015b). Trading up: the fitness consequences of divorce in monogamous birds. Biol. Rev. 90, 1015-1034. doi: $10.1111 /$ brv. 12143

Dale, S., Rinden, H., and Slagsvold, T. (1992). Competition for a mate restricts mate search of female pied flycatchers. Behav. Ecol. Sociobiol. 30, 165-176. doi: 10.1007/BF00166699

David, M., Pinxten, R., Martens, T., and Eens, M. (2015). Exploration behavior and parental effort in wild great tits: partners matter. Behav. Ecol. Sociobiol. 69, 1085-1095. doi: 10.1007/s00265-015-1921-1

Dingemanse, N. J., Both, C., Drent, P. J., and Tinbergen, J. M. (2004). Fitness consequences of avian personalities in a fluctuating environment. Proc. R. Soc. London. Ser. B Biol. Sci. 271, 847-852. doi: 10.1098/rspb.2004.2680

Dubois, F., and Cézilly, F. (2002). Breeding success and mate retention in birds: a meta-analysis. Behav. Ecol. Sociobiol. 52, 357-364. doi: 10.1007/s00265-002-0521-z

Dunn, P. O., and Cockburn, A. (1999). Extrapair mate choice and honest signaling in cooperatively breeding superb fairy-wrens. Evolution $53,938-946$. doi: 10.1111/j.1558-5646.1999.tb05387.x

Englert Duursma, D., Gallagher, R. V., and Griffith, S. C. (2017). Characterizing opportunistic breeding at a continental scale using all available sources of phenological data: an assessment of 337 species across the Australian continent. Auk 134, 509-519. doi: 10.1642/AUK-16-243.1

Englert Duursma, D., Gallagher, R. V., and Griffith, S. C. (2018). Variation in the timing of avian egg-laying in relation to climate. Ecography 42, 565-577. doi: 10.1111/ecog.03602

Fedy, B. C., and Martin, T. E. (2009). Male songbirds provide indirect parental care by guarding females during incubation. Behav. Ecol. 20, 1034-1038. doi: 10.1093/beheco/arp094

Forstmeier, W., and Birkhead, T. R. (2004). Repeatability of mate choice in the zebra finch: consistency within and between females. Anim. Behav. 68, 1017-1028. doi: 10.1016/j.anbehav.2004.02.007

Gabriel, P. O., and Black, J. M. (2012). Behavioural syndromes, partner compatibility and reproductive performance in Steller's Jays. Ethology 118, 76-86. doi: 10.1111/j.1439-0310.2011.01990.x 
Greene, E., Lyon, B. E., Muehter, V. R., Ratcliffe, L., Oliver, S. J., and Boag, P. T. (2000). Disruptive sexual selection for plumage coloration in a passerine bird. Nature 407, 1000-1003. doi: 10.1038/35039500

Griffith, S. C., Crino, O. L., Andrew, S. C., Nomano, F. Y., Adkins-Regan, E., Alonso-Alvarez, C., et al. (2017). Variation in reproductive success across captive populations: methodological differences, potential biases and opportunities. Ethology 123, 1-29. doi: 10.1111/eth.12576

Griffith, S. C., Holleley, C. E., Mariette, M. M., Pryke, S. R., and Svedin, N. (2010). Low level of extrapair parentage in wild zebra finches. Anim. Behav. 79, 261-264. doi: 10.1016/j.anbehav.2009.11.031

Griffith, S. C., Owens, I. P. F., and Thuman, K. A. (2002). Extra pair paternity in birds: a review of interspecific variation and adaptive function. Mol. Ecol. 11, 2195-2212. doi: 10.1046/j.1365-294X.2002.01613.x

Griggio, M., and Hoi, H. (2011). An experiment on the function of the long-term pair bond period in the socially monogamous bearded reedling. Anim. Behav. 82, 1329-1335. doi: 10.1016/j.anbehav.2011.09.016

Hahn, T. P., Watts, H. E., Cornelius, J. M., Brazeal, K. R., and MacDougallShackleton, S. A. (2009). Evolution of environmental cue response mechanisms: adaptive variation in photorefractoriness. Gen. Comp. Endocrinol. 163, 193-200. doi: 10.1016/j.ygcen.2009.04.012

Hall, M. L., and Magrath, R. D. (2007). Temporal coordination signals coalition quality. Curr. Biol. 17, R406-R407. doi: 10.1016/j.cub.2007.04.022

Harris, M. R., and Siefferman, L. (2014). Interspecific competition influences fitness benefits of assortative mating for territorial aggression in Eastern bluebirds (Sialia sialis). PLoS ONE 9:e88668. doi: 10.1371/journal.pone.0088668

Hirschenhauser, K., Mostl, E., and Kotrschal, K. (1999). Within-pair testosterone covariation and reproductive output in Greylag Geese Anser anser. Ibis. 141, 577-586. doi: 10.1111/j.1474-919X.1999.tb07365.x

Hirschenhauser, K., Weiß, B. M., Haberl, W., Möstl, E., and Kotrschal, K. (2010). Female androgen patterns and within-pair testosterone compatibility in domestic geese (Anser domesticus). Gen. Comp. Endocrinol. 165, 195-203. doi: 10.1016/j.ygcen.2009.06.022

Hoelzer, G. A. (1989). The good parent process of sexual selection. Anim. Behav. 38, 1067-1078. doi: 10.1016/S0003-3472(89)80146-0

Horváthová, T., Nakagawa, S., and Uller, T. (2012). Strategic female reproductive investment in response to male attractiveness in birds. Proc. R. Soc. B Biol. Sci. 279, 163-170. doi: 10.1098/rspb.2011.0663

Hosken, D. J., Stockley, P., Tregenza, T., and Wedell, N. (2009). Monogamy and the battle of the sexes. Annu. Rev. Entomol. 54, 361-378. doi: 10.1146/annurev.ento.54.110807.090608

Huxley, J. S. (1914). The Courtship - habits of the Great Crested Grebe (Podiceps cristatus) with an addition to the theory of sexual selection. Proc. Zool. Soc. London 35, 491-562. doi: 10.1111/j.1469-7998.1914.tb07052.x

Huxley, J. S. (1923). Courtship activities of the Red-throated Diver (Colymbus stellatus Pontopp.); together with a discussion on the evolution of Courtship in birds. J. Linn. Soc. London, Zool. 35, 253-292. doi: 10.1111/j.1096-3642.1923.tb00048.x

Huxley, J. S. (1938). Darwin's Theory of Sexual Selection and the Data Subsumed by it, in the Light of Recent Research. Am. Nat. 72, 416-433. doi: $10.1086 / 280795$

Ihle, M., Kempenaers, B., and Forstmeier, W. (2015). Fitness benefits of mate choice for compatibility in a socially monogamous species. PLoS Biol. 13:e1002248. doi: 10.1371/journal.pbio.1002248

Jeschke, J. M., and Kokko, H. (2008). Mortality and other determinants of bird divorce rate. Behav. Ecol. Sociobiol. 63, 1-9. doi: 10.1007/s00265-008-0646-9

Jeschke, J. M., Wanless, S., Harris, M. P., and Kokko, H. (2007). How partnerships end in guillemots Uria aalge: chance events, adaptive change, or forced divorce? Behav. Ecol. 18, 460-466. doi: 10.1093/beheco/arl109

Jetz, W., and Rubenstein, D. R. (2011). Environmental uncertainty and the global biogeography of cooperative breeding in birds. Curr. Biol. 21, 72-78. doi: 10.1016/j.cub.2010.11.075

Johnstone, R. A., and Hinde, C. A. (2006). Negotiation over offspring carehow should parents respond to each other's efforts? Behav. Ecol. 17, 818-827. doi: 10.1093/beheco/arl009

Johnstone, R. A., Manica, A., Fayet, A. L., Stoddard, M. C., Rodriguez-Gironés, M. A., and Hinde, C. A. (2014). Reciprocity and conditional cooperation between great tit parents. Behav. Ecol. 25, 216-222. doi: 10.1093/beheco/art109
Kavelaars, M. M., Lens, L., and Müller, W. (2019). Sharing the burden: on the division of parental care and vocalizations during incubation. Behav. Ecol. 30, 1062-1068. doi: 10.1093/beheco/arz049

Kenny, E., Birkhead, T. R., and Green, J. P. (2017). Allopreening in birds is associated with parental cooperation over offspring care and stable pair bonds across years. Behav. Ecol. 28, 1142-1148. doi: 10.1093/beheco/arx078

Kokko, H., Brooks, R., McNamara, J. M., and Houston, A. I. (2002). The sexual selection continuum. Proc. R. Soc. London. Ser. B Biol. Sci. 269, 1331-1340. doi: $10.1098 / \mathrm{rspb} .2002 .2020$

Leniowski, K., and Wegrzyn, E. (2018a). Equal division of parental care enhances nestling development in the Blackcap. PLoS ONE 13:e0207757. doi: 10.1371/journal.pone.0207757

Leniowski, K., and Wegrzyn, E. (2018b). Synchronisation of parental behaviours reduces the risk of nest predation in a socially monogamous passerine bird. Sci. Rep. 8:7385. doi: 10.1038/s41598-018-25746-5

Lyon, B. E., and Montgomerie, R. (2012). Sexual selection is a form of social selection. Philos. Trans. R. Soc. B Biol. Sci. 367, 2266-2273. doi: $10.1098 /$ rstb.2012.0012

Mainwaring, M. C., and Griffith, S. C. (2013). Looking after your partner: sentinel behaviour in a socially monogamous bird. PeerJ 1:e83. doi: 10.7717/peerj.83

Mariette, M. M., and Griffith, S. C. (2012). Nest visit synchrony is high and correlates with reproductive success in the wild Zebra finch Taeniopygia guttata. J. Avian Biol. 43, 131-140. doi: 10.1111/j.1600-048X.2012.05555.x

Mariette, M. M., and Griffith, S. C. (2015). The adaptive significance of provisioning and foraging coordination between breeding partners. Am. Nat. 185, 270-280. doi: 10.1086/679441

McCowan, L. S. C., Mariette, M. M., and Griffith, S. C. (2015). The size and composition of social groups in the wild zebra finch. Emu 115, 191-198. doi: 10.1071/MU14059

McNamara, J. M., Houston, A. I., Barta, Z., and Osorno, J.-L. (2003). Should young ever be better off with one parent than with two? Behav. Ecol. 14, 301-310. doi: 10.1093/beheco/14.3.301

Nicolai, C. A., Sedinger, J. S., Ward, D. H., and Boyd, W. S. (2012). Mate loss affects survival but not breeding in black brant geese. Behav. Ecol. 23, 643-648. doi: 10.1093/beheco/ars009

Odom, K. J., Hall, M. L., Riebel, K., Omland, K. E., and Langmore, N. E. (2014). Female song is widespread and ancestral in songbirds. Nat. Commun. 5:3379. doi: $10.1038 /$ ncomms4379

Ouyang, J. Q., Sharp, P. J., Dawson, A., Quetting, M., and Hau, M. (2011). Hormone levels predict individual differences in reproductive success in a passerine bird. Proc. R. Soc. B Biol. Sci. 278, 2537-2545. doi: 10.1098/rspb.2010.2490

Ouyang, J. Q., van Oers, K., Quetting, M., and Hau, M. (2014). Becoming more like your mate: hormonal similarity reduces divorce rates in a wild songbird. Anim. Behav. 98, 87-93. doi: 10.1016/j.anbehav.2014.09.032

Parker, G. A., Royle, N. J., and Hartley, I. R. (2002). Intrafamilial conflict and parental investment: a synthesis. Philos. Trans. R. Soc. London. Ser. B Biol. Sci. 357, 295-307. doi: 10.1098/rstb.2001.0950

Petrie, M., Halliday, T., and Sanders, C. (1991). Peahens prefer peacocks with elaborate trains. Anim. Behav. 41, 323-331. doi: 10.1016/S0003-3472(05)80484-1

Pettifor, R. A., Perrins, C. M., and McCleery, R. H. (1988). Individual optimization of clutch size in great tits. Nature 336, 160-162. doi: 10.1038/336160a0

Pilakouta, N., Hanlon, E. J. H., and Smiseth, P. T. (2018). Biparental care is more than the sum of its parts: experimental evidence for synergistic effects on offspring fitness. Proc. R. Soc. B Biol. Sci. 285:20180875. doi: $10.1098 /$ rspb.2018.0875

Psorakis, I., Voelkl, B., Garroway, C. J., Radersma, R., Aplin, L. M., Crates, R. A., et al. (2015). Inferring social structure from temporal data. Behav. Ecol. Sociobiol. 69, 857-866. doi: 10.1007/s00265-015-1906-0

Rogers, A. C., Langmore, N. E., and Mulder, R. A. (2007). Function of pair duets in the eastern whipbird: cooperative defense or sexual conflict? Behav. Ecol. 18, 182-188. doi: 10.1093/beheco/arl070

Roughgarden, J. (2012). The social selection alternative to sexual selection. Philos. Trans. R. Soc. B Biol. Sci. 367, 2294-2303. doi: 10.1098/rstb.2011.0282

Royle, N. J., Hartley, I. R., and Parker, G. A. (2002). Sexual conflict reduces offspring fitness in zebra finches. Nature 416, 733-736. doi: 10.1038/416733a 
Rutstein, A. N., Brazill-Boast, J., and Griffith, S. C. (2007). Evaluating mate choice in the zebra finch. Anim. Behav. 74, 1277-1284. doi: 10.1016/j.anbehav.2007.02.022

Sanchez-Macouzet, O., Rodriguez, C., and Drummond, H. (2014). Better stay together: pair bond duration increases individual fitness independent of age-related variation. Proc. R. Soc. B Biol. Sci. 281:20132843. doi: $10.1098 /$ rspb.2013.2843

Schuett, W., Dall, S. R. X., and Royle, N. J. (2011a). Pairs of zebra finches with similar 'personalities' make better parents. Anim. Behav. 81, 609-618. doi: 10.1016/j.anbehav.2010.12.006

Schuett, W., Godin, J.-G. J., and Dall, S. R. X. (2011b). Do female zebra finches, Taeniopygia guttata, choose their mates based on their 'personality'? Ethology 117, 908-917. doi: 10.1111/j.1439-0310.2011.01945.x

Servedio, M. R., Price, T. D., and Lande, R. (2013). Evolution of displays within the pair bond. Proc. R. Soc. B Biol. Sci. 280:20123020. doi: 10.1098/rspb.2012.3020

Sheldon, B. C. (1994). Male phenotype, fertility, and the pursuit of extra-pair copulations by female birds. Proc. R. Soc. B 257, 25-30. doi: $10.1098 /$ rspb.1994.0089

Slater, P. J. B., and Mann, N. I. (2004). Why do the females of many bird species sing in the tropics? J. Avian Biol. 35, 289-294. doi: 10.1111/j.0908-8857.2004.03392.x

Spoon, T. R., Millam, J. R., and Owings, D. H. (2006). The importance of mate behavioural compatibility in parenting and reproductive success by cockatiels, Nymphicus hollandicus. Anim. Behav. 71, 315-326. doi: 10.1016/j.anbehav.2005.03.034

Stamps, J., Calderón-De Anda, M., Perez, C., and Drummond, H. (2002). Collaborative tactics for nestsite selection by pairs of blue footed boobies. Behaviour 139, 1383-1412. doi: 10.1163/15685390260514672

Symes, L. B., and Price, T. D. (2015). Sexual stimulation and sexual selection. Am. Nat. 185, iii-iv. doi: 10.1086/680414

Tobias, J. A., Gamarra-Toledo, V., Garcia-Olaechea, D., Pulgarin, P. C., and Seddon, N. (2011). Year-round resource defence and the evolution of male and female song in suboscine birds: social armaments are mutual ornaments. J. Evol. Biol. 24, 2118-2138. doi: 10.1111/j.1420-9101.2011.02345.x

van de Pol, M., Heg, D., Bruinzeel, L. W., Kuijper, B., and Verhulst, S. (2006). Experimental evidence for a causal effect of pair-bond duration on reproductive performance in oystercatchers (Haematopus ostralegus). Behav. Ecol. 17, 982-991. doi: 10.1093/beheco/arl036

van Rooij, E. P., and Griffith, S. C. (2013). Synchronised provisioning at the nest: parental coordination over care in a socially monogamous species. PeerJ 1, 1-14. doi: $10.7717 /$ peerj.232
Wachtmeister, C.-A. (2001). Display in monogamous pairs: a review of empirical data and evolutionary explanations. Anim. Behav. 61, 861-868. doi: 10.1006/anbe.2001.1684

Wang, D., Forstmeier, W., and Kempenaers, B. (2017a). No mutual mate choice for quality in zebra finches: time to question a widely held assumption. Evolution 71, 2661-2676. doi: 10.1111/evo.13341

Wang, D., Kempenaers, N., Kempenaers, B., and Forstmeier, W. (2017b). Male zebra finches have limited ability to identify high-fecundity females. Behav. Ecol. 28, 784-792. doi: 10.1093/beheco/arx037

Wasser, D. E., and Sherman, P. W. (2010). Avian longevities and their interpretation under evolutionary theories of senescence. J. Zool. 280, 103-155. doi: 10.1111/j.1469-7998.2009.00671.x

Watts, H. E., Edley, B., and Hahn, T. P. (2016). A potential mate influences reproductive development in female, but not male, pine siskins. Horm. Behav. 80, 39-46. doi: 10.1016/j.yhbeh.2016.01.006

Wedell, N., Kvarnemo, C., Lessells, C. M., and Tregenza, T. (2006). Sexual conflict and life histories. Anim. Behav. 71, 999-1011. doi: 10.1016/j.anbehav.2005.06.023

Weiß, B. M., Kotrschal, K., Möstl, E., and Hirschenhauser, K. (2010). Social and life-history correlates of hormonal partner compatibility in greylag geese (Anser anser). Behav. Ecol. 21, 138-143. doi: 10.1093/beheco/arp164

West-Eberhard, M. J. (1983). Sexual selection, social competition, and speciation. Q. Rev. Biol. 58, 155-183. doi: 10.1086/413215

Wojczulanis-Jakubas, K., Araya-Salas, M., and Jakubas, D. (2018). Seabird parents provision their chick in a coordinated manner. PLoS ONE 13:e0189969. doi: 10.1371/journal.pone.0189969

Zann, R. A. (1996). The Zebra Finch: A Synthesis of Laboratory and Field Studies. Oxford: Oxford University Press.

Conflict of Interest: The author declares that the research was conducted in the absence of any commercial or financial relationships that could be construed as a potential conflict of interest.

Copyright (c) 2019 Griffith. This is an open-access article distributed under the terms of the Creative Commons Attribution License (CC BY). The use, distribution or reproduction in other forums is permitted, provided the original author(s) and the copyright owner(s) are credited and that the original publication in this journal is cited, in accordance with accepted academic practice. No use, distribution or reproduction is permitted which does not comply with these terms. 